\title{
Profile of cancer patients requiring dental and oral-maxillofacial prostheses in a Brazilian subpopulation
}

\author{
Cristiane L. Garcia ${ }^{1}$, Ivan O. Gialain ${ }^{2}$, Maria C.P.F. Volpato ${ }^{3}$, Luiz E.R. Volpato ${ }^{4}$ \\ ${ }^{1}$ DDS, MSc, University of Cuiabá, Cuiabá, Brazil \\ ${ }^{2}$ DDS, MSc, PhD, University of Cuiabá, Cuiabá, Brazil \\ ${ }^{3}$ DDS, MSc, University of Cuiabá and Mato Grosso Cancer Hospital, Cuiabá, Brazil \\ ${ }^{4}$ DDS, MSc, PhD, University of Cuiabá and Mato Grosso Cancer Hospital, Cuiabá, Brazil
}

Correspondence:

Rua Estevão de Mendonça, 317

Goiabeiras, Cuiabá - MT, Brazil

CEP: 78032-085

odontologiavolpato@uol.com.br

Received: 04/11/2021

Accepted: 27/12/202

Garcia CL, Gialain IO, Volpato MCPF, Volpato LER. Profile of cancer patients requiring dental and oral-maxillofacial prostheses in a Brazilian subpopulation. J Clin Exp Dent. 2022;14(2):e131-7.

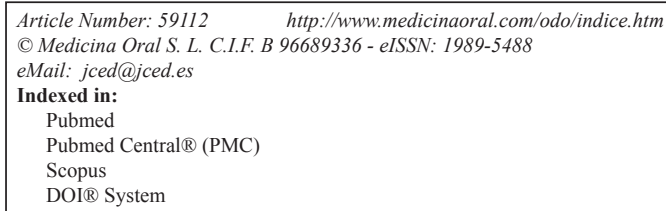

\begin{abstract}
Background: The aim of the present study was to identify the profile of cancer patients in need of rehabilitation with dental and/or oral-maxillofacial prostheses and evaluate possible reasons for not concluding the rehabilitation process.

Material and Methods: A retrospective observational study was conducted at the Dentistry Department of the Mato Grosso Cancer Hospital in the city of Cuiabá, Brazil, involving the analysis of the medical records of patients under care from April 2017 to November 2019.

Results: The study population comprised 256 patients who met the inclusion criteria. A total of $30.90 \%$ of the patients were older adults, $65.6 \%$ were men, $70.3 \%$ had brown skin color, $27.3 \%$ were retired, $49.2 \%$ were married and $52 \%$ resided in municipalities in the state of Mato Grosso other than the capital. A total of $67.23 \%$ reported smoking and 53.9\% reported alcohol consumption. The tumor was located in the head and neck region in 57.4\%. The most frequent histological type was epidermoid carcinoma (55.1\%). A total of $28.9 \%$ of cases were in disease stage IV. Most patients (60.2\%) completed prosthetic rehabilitation, with a predominance of total prosthesis. The main reasons for not completing rehabilitation were the patient's death and weakness.

Conclusions: Patients who started treatment in more advanced stages of cancer had a greater chance of not completing the prosthetic rehabilitation. The non-completion of treatment was directly related to death and the state of weakness.
\end{abstract}

Key words: Cancer, dental prosthesis, epidemiology, maxillofacial prosthesis, oral rehabilitation.

\section{Introduction}

Cancers of the head and neck region profoundly affect the quality of life of patients due to the effect on esthetics, serving as a constant reminder of the disease. These cancers are emotionally draining for patients and their families (1).

Indeed, the diagnosis of cancer exerts a negative impact on the patient's life. Fear and suffering are common 
throughout the process, which begins with the diagnostic phase and is followed by therapy and survival $(2,3)$. Most post-treatment patients whether surgical or not remain in follow-up for an average of 10 years (4).

Cancer treatment has side effects ranging from mild to severe (5). Large facial defects compromise vital functions such as breathing, chewing, speaking and swallowing, as well as esthetics. The prosthetic reconstruction of facial defects helps restore function and assists in the recovery (6).

In the treatment of tumors of the head and neck region, patients are also often submitted to surgeries that have a serious impact on quality of life, appearance and functional characteristics (7). Mutilations of the face can have important esthetic and functional impacts, causing morphofunctional and psychosocial changes that can lead to social isolation. Thus, it is imperative for healthcare providers to commit to the rehabilitation of such patients (8).

Prosthetic treatment is indicated for the recovery of lost oral functions and an improvement in physical appearance, enabling patients to participate in daily activities with greater confidence (9). The absence of teeth not replaced by a prosthesis also exerts a negative impact on the quality of life of cancer patients (10).

Given the need for dental care among cancer patients and the positive impact of rehabilitation on their quality of life, the aim of the present study was to outline the profile of cancer patients rehabilitated with dental and/or oral-maxillofacial prostheses and investigate reasons for the non-completion of rehabilitation process.

\section{Material and Methods}

\section{-Population}

Data collection involved the analysis of the medical records of patients treated at the Dentistry Department of the Cancer Hospital of Mato Grosso in the city of Cuiabá, MT, Brazil, from April 2017 to November 2019. This period was selected because the hospital currently uses a single medical record for each patient and the medical records are managed by an information system that was installed in April 2017.

A search for relevant cases was performed in the Care Management System for the determination of all patients with an indication for prosthetic rehabilitation treatment in the period. Patients of both sexes and of any age were included. Patients having undergone rehabilitation but with no confirmed diagnosis of cancer and those for whom it was not possible to collect data from the respective medical records were excluded.

-Data collection

Data were collected on age, sex, skin color (defined based on the recommendations of the Instituto Brasileiro de Geografia e Estatistica Brazilian Institute of Geography and Statistics]), place of residence (state capital or other municipality), occupation, marital status, smoking habit, drinking habit, family history of cancer.

Characteristics of the disease (tumor location, histological type, stage of the disease and treatment performed [surgery, radiotherapy and chemotherapy]), characteristics of prosthetic rehabilitation (type of maxillary prosthesis [total, partial, total obturator and partial obturator], mandibular prostheses [total or partial], and facial prostheses) and reason for not completing rehabilitation. Patients who met the inclusion criteria but whose medical records did not present information on completing rehabilitation or the installation of the prosthesis were actively contacted by telephone and asked about the reason for not completing rehabilitation treatment. The answers (provided by the patient or family member) were placed into five distinct groups: patient died before completing rehabilitation treatment; patient interrupted treatment because of weakness; patient is still undergoing rehabilitation treatment; patient completed the rehabilitation elsewhere; and no defined response (cases for which telephone contact was unsuccessful).

-Data analysis

A single researcher collected and organized the data on an Excel spreadsheet. Descriptive statistical analysis was performed for the variables of interest. The data were expressed as absolute and relative frequencies. Multinominal logistic regression was performed to analyze possible associations between the independent variables and dependent variables (not completing prosthetic rehabilitation and reason for not completing rehabilitation), as described elsewhere (11). Statistical tests were performed using the SPSS program, version 22.0. Results with a $p$-value $<0.05$ were considered statistically significant.

\section{Results}

Four hundred seventy hospital records were analyzed, 256 of which met the inclusion criteria. Exclusions were due to the non-confirmation of a diagnosis of cancer or the impossibility of collecting data from the medical record.

Age in the sample ranged from 30 to over 70 years. The highest percentage of patients $(30.9 \% ; n=79)$ was between 61 and 70 years of age. The least frequent age group was 30 to 40 years of age $(2.7 \% ; n=7)$. Male patients predominated $(65.6 \% ; n=168)$ over female patients $(34.4 \% ; \mathrm{n}=88)$. The most prevalent skin color was brown $(70.3 \% ; n=180)$. Almost half of the patients resided in the state capital $(48 \% ; \mathrm{n}=123)$ and slightly more than half resided in other municipalities of the state $(52 \% ; n=133)$. Seventy patients $(27.3 \%)$ were retired; 126 patients $(49.2 \%)$ were married; 172 patients reported smoking $(67.2 \%), 138$ patients $(53.9 \%)$ reported alcohol consumption and $130(50.8 \%)$ had a family history of cancer (Table 1). 
Table 1: Distribution of patients according to demographic characteristics, smoking habit, drinking habit and family history of cancer $(n=256)$.

\begin{tabular}{|c|c|c|c|}
\hline Variable & GROUPS & $\mathbf{N}$ & $\%$ \\
\hline \multirow[t]{5}{*}{ Age group } & $30-40$ years & 7 & 2.7 \\
\hline & $41-50$ years & 32 & 12.5 \\
\hline & 51-60 years & 74 & 28.9 \\
\hline & $61-70$ years & 79 & 30.9 \\
\hline & $>70$ years & 64 & 25.0 \\
\hline \multirow[t]{2}{*}{ Sex } & Male & 168 & 65.6 \\
\hline & Female & 88 & 34.4 \\
\hline \multirow[t]{6}{*}{ Skin color/Ethnicity } & Brown & 180 & 70.3 \\
\hline & White & 43 & 16.8 \\
\hline & Black & 23 & 9.0 \\
\hline & Yellow & 4 & 1.6 \\
\hline & Indigenous & 2 & 0.8 \\
\hline & Not declared & 4 & 1.6 \\
\hline \multirow[t]{2}{*}{ Place of residence } & State capital & 123 & 48.0 \\
\hline & Other municipality & 133 & 52.0 \\
\hline \multirow[t]{7}{*}{ Occupation } & Retired & 70 & 27.3 \\
\hline & Housework & 38 & 14.8 \\
\hline & Self-employed & 15 & 5.9 \\
\hline & Rural worker & 12 & 4.7 \\
\hline & Bricklayer & 10 & 3.9 \\
\hline & Other & 53 & 20.7 \\
\hline & Not declared & 58 & 22.7 \\
\hline \multirow[t]{5}{*}{ Marital status } & Single & 78 & 30.5 \\
\hline & Married & 126 & 49.2 \\
\hline & Divorced & 17 & 6.6 \\
\hline & Widow(er) & 16 & 6.3 \\
\hline & Not declared & 19 & 7.4 \\
\hline \multirow[t]{3}{*}{ Smoking habit } & Yes & 172 & 67.2 \\
\hline & No & 80 & 31.3 \\
\hline & Not declared & 4 & 1.6 \\
\hline \multirow[t]{3}{*}{ Alcohol consumption } & Yes & 138 & 53.9 \\
\hline & No & 113 & 44.1 \\
\hline & Not declared & 5 & 2.0 \\
\hline \multirow[t]{3}{*}{ Family history of cancer } & Yes & 130 & $\overline{50.8}$ \\
\hline & No & 114 & 44.5 \\
\hline & Not declared & 12 & 4.7 \\
\hline
\end{tabular}

Regarding cancer treatment, 180 patients $(70.3 \%)$ underwent surgery, $182(71.1 \%)$ underwent radiotherapy and $162(63.3 \%)$ underwent chemotherapy. The most frequent tumor location was the head and neck region $(57.4 \% ; \mathrm{n}=147)$, followed by the breast $(12.1 \% ; \mathrm{n}=$ 31 ). The most frequent histological type was squamous cell carcinoma $(55.1 \% ; \mathrm{n}=141)$. Among the patients with data on the stage of the disease when the diagnosis was made, 74 (28.9\%) were in stage IV (Table 2).

Among the 256 medical records analyzed, 154 patients $(60.2 \%)$ completed prosthetic rehabilitation and 102 (38.8\%) did not complete rehabilitation at the Dentistry Department of the Mato Grosso Cancer Hospital. Among the 154 patients who completed the rehabilita- 
Table 2: Distribution of patients according to tumor characteristics (location, histological type, staging) and cancer treatments performed (surgery, radiotherapy and chemotherapy) $(\mathrm{n}=256)$.

\begin{tabular}{|c|c|c|c|}
\hline Variable & GROUPS & $\mathbf{N}$ & $\%$ \\
\hline \multirow[t]{6}{*}{ Tumor location } & Head and neck & 147 & 57.4 \\
\hline & Breast & 31 & 12.1 \\
\hline & Prostate & 26 & 10.2 \\
\hline & Digestive system & 22 & 8.6 \\
\hline & Other & 26 & 10.2 \\
\hline & Not declared & 4 & 1.6 \\
\hline \multirow[t]{6}{*}{ Histological type } & Epidermoid carcinoma & 141 & 55.1 \\
\hline & Ductal carcinoma & 23 & 9.0 \\
\hline & Adenocarcinoma & 45 & 17.6 \\
\hline & Non-Hodgkin lymphoma & 9 & 3.5 \\
\hline & Other & 26 & 10.2 \\
\hline & Not declared & 12 & 4.7 \\
\hline \multirow[t]{5}{*}{ Staging } & I & 9 & 3.5 \\
\hline & II & 23 & 9.0 \\
\hline & III & 46 & 18.0 \\
\hline & IV & 74 & 28.9 \\
\hline & Not declared & 104 & 40.6 \\
\hline \multirow[t]{2}{*}{ Surgery } & Yes & 180 & 70.3 \\
\hline & No & 76 & 29.7 \\
\hline \multirow[t]{2}{*}{ Radiotherapy } & Yes & 182 & 71.1 \\
\hline & No & 74 & 28.9 \\
\hline \multirow[t]{2}{*}{ Chemotherapy } & Yes & 162 & 63.3 \\
\hline & No & 94 & 36.7 \\
\hline
\end{tabular}

tion treatment, $148(96.01 \%)$ received a maxillary prosthesis, among which $102(68.9 \%)$ were total prostheses, $35(23.6 \%)$ were partial prostheses, nine (6.1\%) were total obturators and two (1.4\%) were partial obturators. Among the $126(81.8 \%)$ patients who received a mandibular prosthesis, $81(64.3 \%)$ were total prostheses and $45(35.7 \%)$ partial prostheses. Three patients received facial prostheses (1.2\%). Among the 102 patients who did not complete rehabilitation, 30 (29.4\%) died before completing prosthetic treatment, $26(25.5 \%)$ were very debilitated by the disease or had health problems that prevented the continuation of rehabilitation, $18(17.6 \%)$ were still undergoing rehabilitation, 10 (9.8\%) finished treatment elsewhere and 18 (17.6\%) qualified for "undefined reason for not concluding treatment", as contact via telephone was not possible (Fig. 1).

Multivariate logistic regression was performed to investigate associations between the patient characteristics (age, staging, place of residence and marital status) and the completion/non-completion of prosthetic rehabilitation. Patients with advanced stages of cancer were less likely to complete treatment ( $p=0.048$ ), whereas no other independent variables (age, place of residence or marital status) were significantly associated with the completion/non-completion of prosthetic rehabilitation (Table 3).

Multivariate logistic regression was also performed to investigate associations between the patient characteristics (age, place of residence and stage of cancer) and the reason why prosthetic rehabilitation was not completed (patient was very weak, patient still undergoing prosthetic treatment, completed rehabilitation elsewhere, death or no defined reason). A statistically significant association was found between the stage of cancer and not having completed prosthetic rehabilitation due to weakness ( $p=$ $0.041)$. A significant association was also found between cancer staging and completed treatment elsewhere $(p=$ 0.007 ), as patients in more advanced stages were less likely to complete prosthetic rehabilitation at the Cancer Hospital of Mato Grosso. Place of residence and age were not significantly associated with the reason for the non-completion of prosthetic treatment (Table 4). 


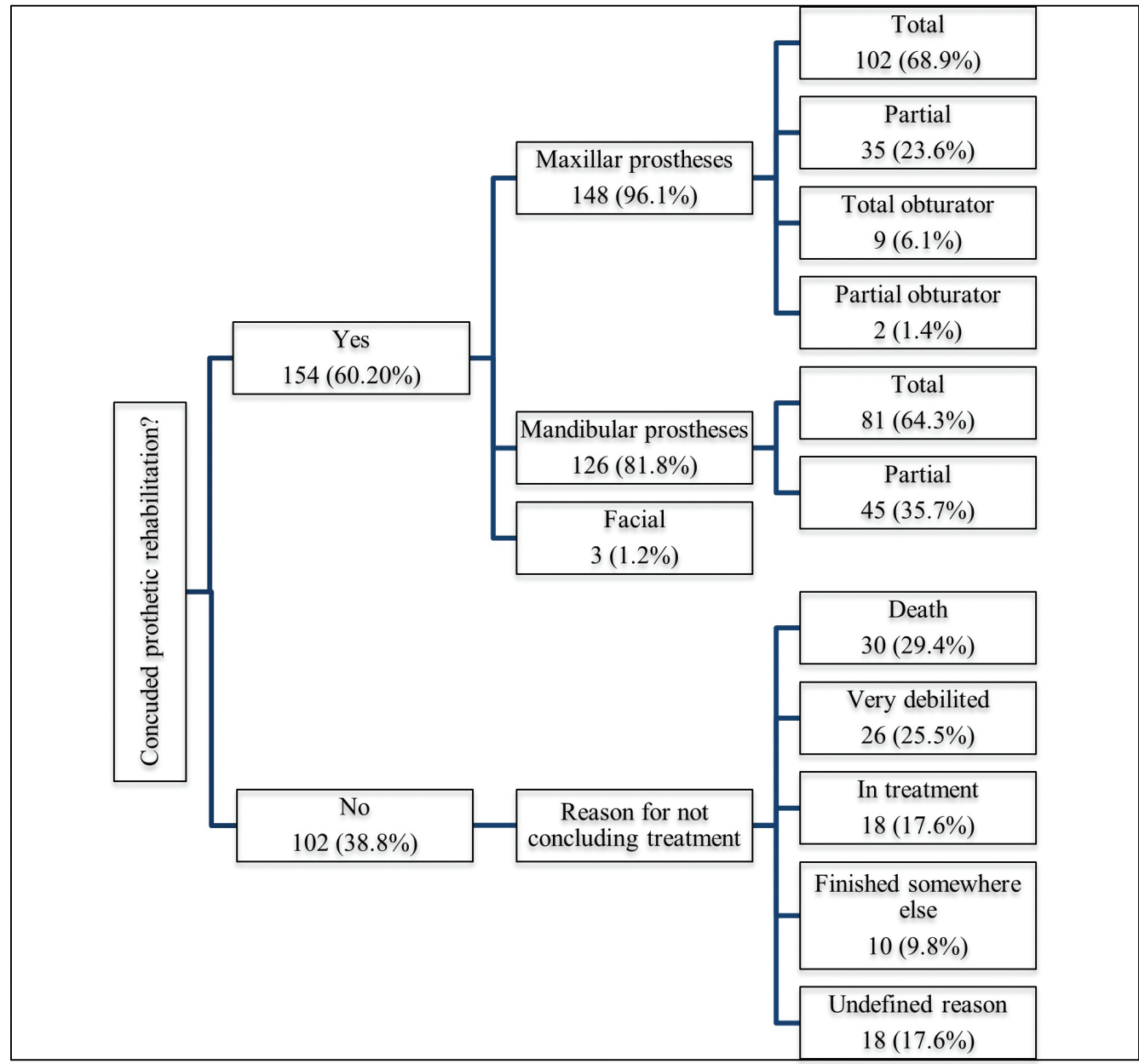

Fig. 1: Flowchart of prosthetic rehabilitation characteristics and reasons for not completing prosthetic treatment.

Table 3: Results of multivariate logistic regression analysis of completion of prosthetic rehabilitation according to patient characteristics (age, marital status, place of residence and cancer staging).

\begin{tabular}{|l|c|c|c|c|}
\hline Explanatory variable & B & $\boldsymbol{P}$ & ODDS RATIO & 95\% CI \\
\hline Age & -0.214 & 0.214 & 0.807 & $0.576-1.132$ \\
\hline Staging & -0.425 & 0.048 & 1.530 & $1.003-2.333$ \\
\hline Place of residence & 0.017 & 0.962 & 1.017 & $0.497-2.082$ \\
\hline Marital status & 0.662 & 0.078 & 1.938 & $0.928-4.050$ \\
\hline
\end{tabular}

* Overall chi-square $=9.095$ with 40 of freedom and $p=0.059$.

\section{Discussion}

The present findings show that cancer patients rehabilitated with dental and/or maxillofacial prostheses are mainly older adults and the main reason for not concluding treatment was the patient's death. The population studied was predominantly male, married and retired. A total of 52\% of the patients resided in municipalities other than the capital city and $70.3 \%$ had brown skin color. Caetano et al. (12) evaluated quality of life, body image and self-esteem in patients with sequelae following treatment for head and neck cancer, who were candidates for prosthetic rehabilitation. In the sample of 10 patients, the male sex predominated $(60 \%), 50 \%$ were married, $30 \%$ were 51 to 60 years of age, $40 \%$ were farmers, $30 \%$ were retired and $60 \%$ resided in municipalities other than the state capital. In a study by Rettig and D'Souza (13), the two of the main causes of head and neck cancer were the use of tobacco and alcohol. Gomes et al. (14) analyzed 33 patients, $84.38 \%$ and $87.50 \%$ of whom formerly used or still used tobacco and alcohol, respectively. 
Table 4: Results of multivariate ana logistic regression analysis of reasons for not completing prosthetic rehabilitation according to patient characteristics (age, place of residence and cancer staging).

\begin{tabular}{|l|c|c|c|c|c|}
\hline Category & Explanatory variable & B & $\boldsymbol{p}$ & ODDS RATIO & $\mathbf{9 5 \%}$ CI \\
\hline \multirow{3}{*}{ Without defined reason } & Staging & -0.449 & 0.525 & 0.638 & $0.160-2.544$ \\
\cline { 2 - 6 } & Place of residence & -0.046 & 0.955 & 0.955 & $0.194-4.698$ \\
\cline { 2 - 6 } & Age & -0.163 & 0.637 & 0.850 & $0.431-1.673$ \\
\hline \multirow{3}{*}{ Debilitated patient } & Staging & -1.128 & $\mathbf{0 . 0 4 1}$ & 0.324 & $0.110-0.953$ \\
\cline { 2 - 6 } & Place of residence & 1.176 & 0.101 & 3.241 & $0.794-13.23$ \\
\cline { 2 - 6 } & Age & 0.079 & 0.794 & 1.083 & $0.597-1.961$ \\
\hline \multirow{3}{*}{ Undergoing treatment } & Staging & -1.032 & 0.074 & 0.356 & $0.115-1.107$ \\
\cline { 2 - 6 } & Place of residence & 0.244 & 0.742 & 1.277 & $0.298-5.465$ \\
\cline { 2 - 6 } & Age & -0.224 & 0.480 & 0.799 & $0.429-1.489$ \\
\hline Complete elsewhere & Staging & -2.073 & $\mathbf{0 . 0 0 7}$ & 0.126 & $0.028-0.563$ \\
\cline { 2 - 6 } & Place of residence & 0.243 & 0.869 & 1.275 & $0.070-23.15$ \\
\cline { 2 - 6 } & Age & -0.952 & 0.106 & 0.386 & $0.122-1.224$ \\
\hline
\end{tabular}

* Overall chi-square $=20.483$ with $12 \mathrm{o}$ of freedom and $p=0.058$.

The anatomical sites most affected by tumors in the present sample were the head/neck (57.4\%), breast (12.1\%) and prostate $(10.3 \%)$. Breast and prostate cancer are among the most prevalent forms of cancer in Brazil (15). The greater number of patients with tumors in the head and neck region in the present study may be explained by the fact that these patients have their oral health analyzed in the Dentistry Department before starting antineoplastic treatment and therefore already established a connection with the department, subsequently returning for oral rehabilitation.

The most frequent histopathological diagnosis was epidermoid carcinoma $(55.1 \% ; \mathrm{n}=141)$ and the most frequent disease stage was IV $(28.9 \% ; \mathrm{n}=74)$. Epidermoid carcinoma is the most frequent malignancy among tumors of the head and neck region and the sixth most common cancer globally (16).

One hundred fifty-four patients $(60.2 \%$ of the population studied) completed prosthetic rehabilitation, involving a total of three facial prostheses, 148 maxillary prostheses including 11 obturators and 126 mandibular prostheses. Quispe et al. (17) evaluated 75 individuals, but only 30 were cancer patients. The authors assessed the need for maxillary and mandibular prostheses and found the following results: 21 patients needed a maxillary prosthesis to replace one tooth $(10 \%)$ or to replace more than one tooth $(33.3 \%)$, needed a combination of prostheses $(13.3 \%)$ or needed a total prosthesis $(13.7 \%)$ and 29 patients used a mandibular prosthesis to replace more than one tooth $(70 \%)$, required a combination of prostheses $(3.3 \%)$ or required a total prosthesis $(23.7 \%)$. According to Joo et al. (7), patients undergoing oncological treatment may have several sequelae that can impair chewing function, swallowing and esthetics. Thus, the use of a total or partial obturator is an option to remedy such se- quelae and enable a better quality of life. Parameswari et al. (18) also concluded that prosthetic rehabilitation with an obturator restores the missing intraoral structures and acts as an anatomical barrier between the oral and nasal cavities, restoring function and esthetics.

This study was conducted at the Cancer Hospital of Mato Grosso located in the city of Cuiabá, Brazil. The hospital uses a single medical record for each patient, regardless of the treatments performed in different departments of the institution. The medical records lacked some relevant information, which likely exerted an influence on the analysis and constitutes a limitation of the present study. Such a limitation is often found in studies involving the analysis of secondary data from databases not collected specifically for the research. However, this aspect is compensated by the possibility of providing information on a large number of patients over an extended period of time in a fast, agile manner (19).

\section{Conclusions}

The patients rehabilitated with dental and maxillofacial prostheses in the present study were mainly male, older, married, individuals with brown skin residing in municipalities other than the capital city who smoked, consumed alcohol and had a history of cancer in the family. The tumor was located in the head and neck region in $57.4 \%$. The most frequent histological type was epidermoid carcinoma (55.1\%). A total of $28.9 \%$ of cases were in disease stage IV. The patients underwent surgery, radiotherapy and chemotherapy. Total prosthesis was the most common form of rehabilitation. Patients who started treatment in more advanced stages of cancer had a greater chance of not completing prosthetic rehabilitation and the main reasons for the non-completion of treatment were death and weakness. 


\section{References}

1. Lemon JC, Kiat-amnuay S, Gettleman L, Martin JW, Chambers MS. Facial prosthetic rehabilitation: preprosthetic surgical techniques and biomaterials. Curr Opin Otolaryngol Head Neck Surg. 2005;13:25562.

2. Ness S, Kokal J, Fee-Schroeder K, Novotny P, Satele D, Barton D. Concerns across the survivorship trajectory: results from a survey of cancer survivors. Oncol Nurs Forum. 2013;40:35-42.

3. Krakow MC, Girardon-Perlini CMO, Stamm B, Camponogara S. Experience of families facing the revelation of the cancer diagnosis in one of its integrants. Rev Min Enferm. 2015;19:747-75.

4. Lopes JV, Bergerot CD, Barbosa LR, Calux NMCT, Elias S, Ashing $\mathrm{KT}$, et al. Impact of breast cancer and quality of life of women survivors. Rev. Bras. Enferm. 2018;71:2916-21.

5. Costa AC, Silva GC, Silva Filho OFS. Acupuncture in support chemotherapy treatment: an integrative review. R. Interd. 2017;10:18091.

6. Vickery LE, Latchford G, Hewison J, Bellew M, Feber T. The impact of head and neck cancer and facial disfigurement on the quality of life of patients and their partners. Head Neck 2003;2013:289-96

7. Joo YH, Cho JK, Koo BS, Kwon M, Kwon SK, Kwon SY, et al. Guidelines for the Surgical Management of Oral Cancer: Korean Society of Thyroid-Head and Neck Surgery. Clin Exp Otorhinolaryngol. 2019;12:107-44.

8. Volpato LE, Kloster AP, Nunes LF, Pedro FLM, Borges AH. Cariogenic microbiota of children under chemotherapy: A pilot study. $\mathrm{J}$ Indian Soc Pedod Prev Dent. 2016;34:370-6.

9. Cotic J, Jamsek J, Kuhar M, Hren NI, Kansky A, Özcan M, et al. Implant-prosthetic Rehabilitation After Radiation Treatment in Head and Neck Cancer Patients: A Case-Series Report of Outcome. Radiol Oncol. 2016;51:94-100.

10. Romeo U, Lollobrigida M, Palaia G, Laurito D, Cugnetto R, De Biase A. Soft tissue management and prosthetic rehabilitation in a tongue cancer patient. Case Rep Dent. 2013;2013:475186.

11. Flores-Ruiz R, Castellanos-Cosano L, Serrera-Figallo MA, Gutiérrez-Corrales A, Gonzalez-Martin M, Gutiérrez-Pérez JL, et al. Evolution of oral cancer treatment in na andalusian population sample: Rehabilitation with prosthetic obturation and removable partial prosthesis. J Clin Exp Dent. 2017;9:e1008-14.

12. Caetano RDS, Volpato LER, Castro PHS, Borba AM. Smoking influences the Occurrence of Radiodermatitis in Head and Neck-irradiated Patients. WJD. 2017;8:55-8.

13. Rettig EM, D'Souza G. Epidemiology of head and neck cancer. Surg Oncol Clin N Am. 2015;24:379-96.

14. Gomes EPAA, Aranha AMF, Borges AH, Volpato LER. Head and Neck Cancer Patients' Quality of Life: Analysis of Three Instruments. J Dent (Shiraz). 2020;21:31-41.

15. Jethwa AR, Khariwala SS. Tobacco-related carcinogenesis in head and neck cancer. Cancer Metastasis Rev. 2017;36:411-23.

16. Lacko M, Braakhuis BJ, Sturgis EM, Boedeker CC, Suárez C, Rinaldo A, et al. Genetic susceptibility to head and neck squamous cell carcinoma. Int J Radiat Oncol Biol Phys. 2014;89:38-48.

17. Quispe RA, Cremonesi AL, Gonçalves JK, Rubira CMF, Santos PSS. Case-control study of oral disease indexes in individuals with head and neck cancer after antineoplastic therapy. Einstein. 2018;16:eAO4245.

18. Parameswari BD, Rajakumar M, Jagadesaan N, Annapoorni H. Case Presentation of Two Maxillectomy Patients Restored with Two-piece Hollow Bulb Obturator Retained using Two Different Types of Magnets. J Pharm Bioallied Sci. 2017;9:S252-6.

19. Volpato LER, Scatena JH. Analysis of the oral health policy of Cuiabá Municipality, Mato Grosso State, Brazil, using the outpatient Information System database of the national Public Health System (SIA-SUS). Epidemiol Serv Saúde. 2006;15:47-55.

\section{Ethics}

This study received approval from the institutional review board of the University of Cuiabá (process number: 3.740 .742 ).

\section{Source of Funding}

This study received no funding.

\section{Conflict of interest}

The authors declare having no financial and personal relationships with other people or organizations that could inappropriately influence (bias) this work. 